\title{
On the relation between Meridional Overturning Circulation and sea-level gradients in the Atlantic
}

\author{
H. Kienert and S. Rahmstorf \\ Potsdam Institute for Climate Impact Research, Telegrafenberg A62, 14473 Potsdam, Germany \\ Correspondence to: H. Kienert (kienert@ pik-potsdam.de)
}

Received: 2 April 2012 - Published in Earth Syst. Dynam. Discuss.: 18 April 2012

Revised: 21 August 2012 - Accepted: 27 August 2012 - Published: 24 September 2012

\begin{abstract}
On the basis of model simulations, we examine what information on changes in the strength of the Atlantic Meridional Overturning Circulation (AMOC) can be extracted from associated changes in sea surface height (SSH), specifically from a broad Atlantic north-south gradient as has been suggested previously in the literature. Since a relation between AMOC and SSH changes can only be used as an AMOC diagnostic if it is valid independently of the specific forcing, we consider three different forcing types: increase of $\mathrm{CO}_{2}$ concentration, freshwater fluxes to the northern convection sites and the modification of Southern Ocean winds. We concentrate on a timescale of $100 \mathrm{yr}$. We find approximately linear and numerically similar relations between a sea-level difference within the Atlantic and the AMOC for freshwater as well as wind forcing. However, the relation is more complex in response to atmospheric $\mathrm{CO}_{2}$ increase, which precludes this sea-level difference as an AMOC diagnostic under climate change. Finally, we show qualitatively to what extent changes in SSH and AMOC strength, which are caused by simultaneous application of different forcings, correspond to the sum of the changes due to the individual forcings, a potential prerequisite for more complex SSHbased AMOC diagnostics.
\end{abstract}

\section{Introduction}

Due to the associated heat transport, the AMOC plays an important role for the climate in the regions surrounding the North Atlantic (NA). It was suggested $25 \mathrm{yr}$ ago that its strength is likely to be significantly influenced by global warming and consequent changes in the climate system (Broecker, 1987). While this connection was later confirmed by model experiments (Manabe and Stouffer, 1993; Gregory et al., 2005), quantitative predictions are not yet robust and all models may contain systematic biases (Hofmann and Rahmstorf, 2009). Monitoring the AMOC is a challenge, since direct measurements, e.g. as conducted by the RAPID array (Kanzow et al., 2008) are difficult and locally confined. Thus, complementary indirect observations via more accessible ocean properties would be desirable. For example, an index correlating a characteristic dipole pattern of sea surface temperature between the North and South Atlantic with the AMOC was proposed by Latif et al. (2004). This index has been applied to observations of the 20th century (Latif et al., 2006), and a decadal MOC variability of 1.5 to $3 \mathrm{~Sv}$ was found. However, it remains open to what extent this index reflects factors other than the AMOC, e.g. aerosol-forced cooling in the Northern Hemisphere.

Previous research on a scaling between the AMOC strength and meridional density gradients was based on geostrophy, either keeping the relevant depth scale fixed or variable (e.g. Bryan, 1987; Gnanadesikan, 1999). Under the assumption of a fixed level of no motion and thus no horizontal mass redistribution, the changes in density can be directly related to changes in sea-level height. In his conceptual box model, Stommel (1961) has applied a linear relation between the density gradient and overturning strength with a fixed scale depth. Also Hughes and Weaver (1994) and Thorpe et al. (2001) have considered a fixed depth (of $3000 \mathrm{~m}$ ) up to which density differences are integrated. Changes in these resulting steric height differences (corresponding to changes in sea level if mass redistribution is neglected) have been shown to linearly scale with AMOC changes under increasing $\mathrm{CO}_{2}$ concentrations. This indicates that sea level alone might be a useful diagnostic for the overturning strength. 
However, for AMOC changes induced by freshwater forcing, a much higher value for the slope of the linear relation has been found (Hu et al., 2004). Furthermore, the relation of the AMOC and steric height differences as defined in Thorpe et al. (2001) has been shown to break down in case of AMOC changes remotely forced by modifications of the Southern Ocean winds (de Boer et al., 2010).

So far, sea level data from satellites is used in conjunction with data on sea surface temperature and winds in order to determine ocean surface currents (Dohan and Maximenko, 2010). But due to the vertical structure, this is not sufficient for explicitly and locally determining depth-integrated velocities. Ivchenko et al. (2011) show that a large part of the sealevel variability at $26.5^{\circ} \mathrm{N}$ is caused by density changes in the upper $200 \mathrm{~m}$, which hardly influence the total transport. So, for its calculation, the full density field is additionally needed. Taking into account such data, which can be obtained from ARGO measurements, Willis (2010) has reconstructed the transport of the upper limb of the AMOC at a specific location.

One approach to detect changes in the maximum of the AMOC streamfunction by using solely sea level data is based on the possibly strong connection of the AMOC and the subpolar-gyre strength (Lee et al., 2010). The variability of the latter is estimated by Häkkinen (2001) as the principal component of the first EOF from North Atlantic altimeter measurements; and he shows on the basis of model experiments that it is highly correlated with meridional heat transport, which he takes as a measure for AMOC strength. While these SSH patterns are thus potentially a diagnostic for AMOC variability, it remains unclear whether a similar picture would emerge for future AMOC changes on a longer timescale or with different origins. Spatial patterns of sealevel change have also been analyzed for simulated future climate scenarios (e.g. Yin et al., 2009 and Landerer et al., 2007), and resulting patterns are partly attributed to a shift in the location of the North Atlantic Current (NAC). For two different global-warming scenarios, Körper et al. (2009) observe an increased sea level rise in the northern part of the North Atlantic, which is caused by changes of heat content and salinity between $112.5 \mathrm{~m}$ and $1200 \mathrm{~m}$ depth, and these changes are associated with a weakening of the AMOC. Still, it is an open question if these patterns are in a one-to-one correspondence with AMOC changes for different forcing types, strengths and times.

As an alternative to the attempt of identifying more or less complex spatial patterns of sea-level change, which are related to the AMOC strength, it is worth considering a simple large scale north-south gradient of sea-level rise. Levermann et al. (2005) have found such a distinct gradient in response to a freshwater-induced shutdown of the AMOC in idealized model simulations (Fig. 1). A similar pattern was also observed in the model average of SSH changes in the CMIP3 warming scenarios of the IPCC-AR4 (Meehl et al., 2007). This sea surface height anomaly $\eta$ must be

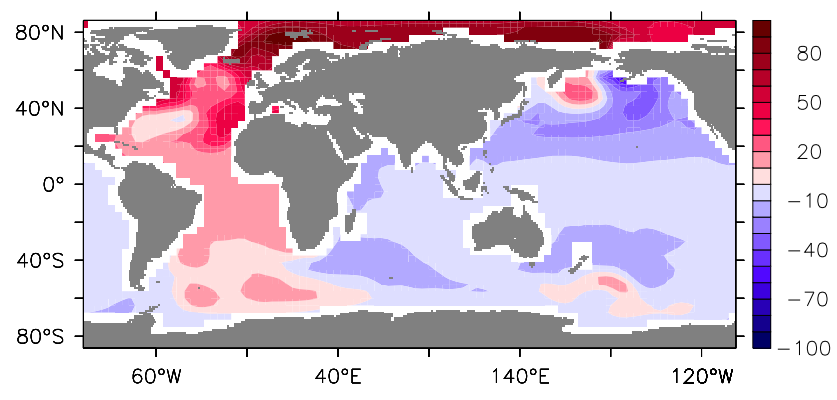

Fig. 1. Equilibrium dynamic sea level change (in $\mathrm{cm}$ ) after freshwater induced collapse of the AMOC $(800 \mathrm{yr}$ of forcing as in Levermann et al., 2005).

approximately related via geostrophy to anomalies $u$ of zonal surface velocities:

$f u=-\frac{1}{\rho_{0}} \frac{\partial p}{\partial y} \approx-g \frac{\partial \eta}{\partial y}$,

where $f$ is the Coriolis parameter. Only the upper branch of the MOC (in contrast to the currents contributing to the Gyres) crosses the Atlantic without a surface return flow: once from east to west in the South Atlantic, and then in the opposite direction mainly as the North Atlantic Current (NAC). Therefore, we expect a broad meridional SSH gradient to correspond at least to the surface velocities belonging to the AMOC. The idea of a correspondence with depth integrated transport has been further pursued by Lorbacher et al. (2010). In agreement with Levermann et al. (2005), they indeed find that a freshwater induced weakening of the AMOC is well correlated to a broad SSH rise in the NA relative to the South. While this is an encouraging result, it remains open if it also holds for AMOC changes induced by higher $\mathrm{CO}_{2}$ concentrations under climate change or by remote forcing as in case of Southern Ocean winds. Also, Lorbacher et al. (2010) take into account only a single simulation and thus a single forcing strength. Therefore, it is also necessary to find out whether the linear relation is valid - and numerically identical - for a sufficiently large parameter range. All of this must be fulfilled in order to use such a relation for diagnosing AMOC changes.

After a description of the model and the simulations in Sect. 2, we first compare (transient) sea-level patterns resulting from three different forcing types in Sect. 3. Following this, we present and analyze relations between the SL gradient and AMOC changes based on simulations covering $\mathrm{CO}_{2}$, freshwater and Southern Ocean Wind forcing with several different strengths each (Sect. 4). Finally, in Sect. 5, we will shortly discuss from a more general perspective of SL-based AMOC diagnostics, how well SL and AMOC changes due to simultaneous application of different forcings match the sum of the changes caused by the individual forcings. 


\section{Model simulations}

All simulations have been performed with the Earth System Model of Intermediate Complexity CLIMBER-3 $\alpha$ (Montoya et al., 2005) which is based on the ocean model MOM-3 (Pacanowski and Griffies, 1999) and a statistical-dynamical atmosphere (Petoukhov et al., 2000). The ocean module has a non-eddying horizontal resolution of $3.75^{\circ}$ and a vertical resolution of 24 layers, which together with the simplified atmosphere renders the model computationally efficient for the relevant ensemble studies. Vertical mixing in the boundary layer is parameterized via the $\mathrm{kpp}$-scheme (Large et al., 1994). The background values are $0.3 \mathrm{~cm}^{2} \mathrm{~s}^{-1}$ for vertical diffusivity and $10 \mathrm{~cm}^{2} \mathrm{~s}^{-1}$ for vertical viscosity. Isoneutral mixing is accomplished via Redi diffusion (Redi, 1982 ) with a diffusivity of $2.0 \times 10^{7} \mathrm{~cm}^{2} \mathrm{~s}^{-1}$ and GentMcWilliams eddy stirring (Gent and McWilliams, 1990) with $0.25 \times 10^{7} \mathrm{~cm}^{2} \mathrm{~s}^{-1}$. A nonlinear explicit free surface formulation is used so that sea level is a prognostic variable and does not need to be diagnosed.

For our analysis of the relation between sea surface height and the AMOC, we focus on changes caused by freshwater fluxes into the northern convection sites, increases of $\mathrm{CO}_{2}$ concentration as well as modifications of Southern Ocean wind stress. All three forcings are known to determine the AMOC strength (Kuhlbrodt et al., 2007). The first two are additionally motivated by climate change since greenhouse gas concentrations have been rising and higher temperatures result in larger meltwater runoff from the Greenland ice sheet. The Southern Ocean wind changes are a remote forcing quite different from the others, and it may indicate if a relation between AMOC and SL is universal or just consists of two separate reactions to local buoyancy forcing. However, it is not certain in how far the response of the Southern Ocean to this forcing would be different in eddy-permitting simulations, because energetic eddies might partly compensate the reaction of the Ekman transport (e.g. Farneti and Delworth, 2010; Farneti et al., 2010; Spence et al., 2010).

If not otherwise mentioned, all simulations are started from an equilibrium state under preindustrial conditions $\left(\mathrm{CO}_{2}\right.$ concentration of $\left.280 \mathrm{ppm}\right)$, and forcing strengths are linearly increased within $100 \mathrm{yr}$ from zero to a value which we will in the following call target value. Freshwater forcing has been applied as a negative salt flux in the region between $52^{\circ} \mathrm{N}$ and $80^{\circ} \mathrm{N}$ as well as $48^{\circ} \mathrm{W}$ and $15^{\circ} \mathrm{E}$, excluding shallow areas over the continental shelves (same forcing area as in Fig. 1). The flux has been compensated in the Pacific ocean. The Southern Ocean wind stress anomalies have been applied south of $31.875^{\circ} \mathrm{S}$. As our emphasis is on better understanding the principle relations underlying the three forcings, we exclude feedbacks involving wind stress by keeping it fixed at its climatological values unless modified explicitly. Since we exclusively focus on relative regional sea level rise, changes in global sea level have been subtracted for all model results in the paper.

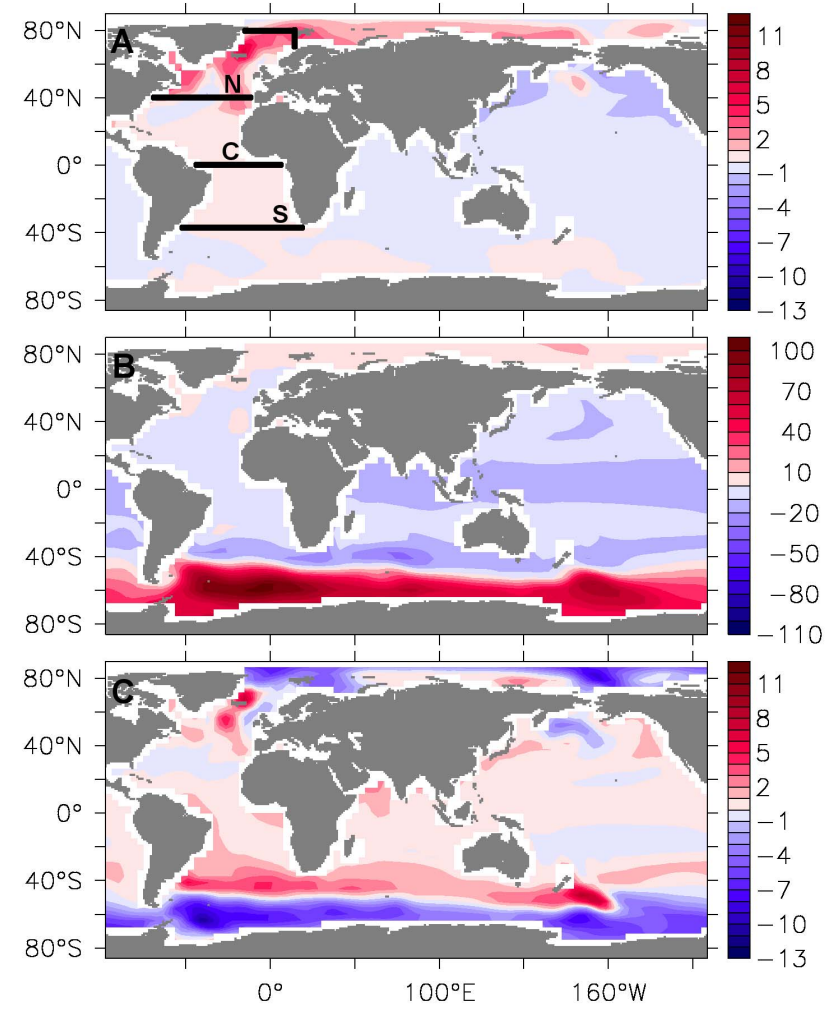

Fig. 2. Dynamic sea level rise in $\mathrm{cm} \mathrm{Sv}^{-1}$ (i.e. normalized to a weakening of the AMOC by $1 \mathrm{~Sv}$ ), after $100 \mathrm{yr}$ of the following forcings: (A) freshwater with a target value of $0.064 \mathrm{~Sv}$, (B) Southern Ocean winds approaching zero, $(\mathbf{C}) \mathrm{CO}_{2}$ with a target concentration of $500 \mathrm{ppm}$.

\section{SSH patterns resulting from the three different forcings}

We first compare the sea-level anomalies resulting from $100 \mathrm{yr}$ of simulation under the three different types of forcing and several different strengths. The patterns have been divided by the amount of AMOC reduction induced by this forcing for normalization (Fig. 2). The target value of the applied freshwater forcing is $0.064 \mathrm{~Sv}$ leading to an AMOC weakening of $2.0 \mathrm{~Sv}$. In order to get a sufficiently strong reduction of the AMOC after these first $100 \mathrm{yr}$, we let the Southern Ocean wind stress approach zero, which results in a change of the AMOC streamfunction maximum by $-1.24 \mathrm{~Sv}$. The final $\mathrm{CO}_{2}$ concentration amounts to $500 \mathrm{ppm}$ concomitant with an AMOC weakening of $2.0 \mathrm{~Sv}$ as in the case of freshwater forcing.

In case of freshwater forcing (top panel), the most prominent pattern is a rise of sea level in the Atlantic north of $40^{\circ}$ which includes the forcing area. A contribution to this effect is given by the reduction of convection due to the freshwater lid leading to a weakening of the local ocean-atmosphere heat flux. It is interesting to observe that no significant effects 
on sea level are transmitted to more distant regions, e.g. the South Atlantic.

A reduction of the Southern Ocean wind stress (middle panel) also results primarily in a localized sea level reaction. The surface currents in the ACC region are directly slowed down and sea level south of the ACC rises as expected from geostrophy. However, the SL difference in the Atlantic section of the Southern Ocean is not linearly linked to the AMOC when the latter increases and decreases in strength due to modifications of the wind stress (not shown).

The overturning strength is of course not in equilibrium after these first $100 \mathrm{yr}$. In year 500 , from when onwards the AMOC maximum remains rather constant (or oscillates around a quite stable value), the sea-level response turns out to be less localized with a reaction in the North Atlantic for the wind stress forcing, and a reaction in the Southern Ocean in the case of freshwater forcing.

In case of rising $\mathrm{CO}_{2}$ concentration (bottom panel), we apply a global forcing and indeed significant adaptations of sea level height are induced in multiple regions. The most prominent features are a relative rise of sea level in the convection areas of the North Atlantic as well as a drop of sea level in the Weddell Gyre and to a lesser extent in further domains south of the ACC.

Comparing these three figures, we can not identify a common sea-level pattern, which could directly correspond to a change of the AMOC maximum independently of the forcing type. However, Fig. 2 supports the link between a systematic north-south SL gradient in the Atlantic and the AMOC which has been discussed above. In the following section, we will thus analyze the relation of AMOC changes and SL differences between three parts of a subdivided Atlantic Ocean: (N)orth, (C)entral and (S)outh, bounded by the $80^{\circ}$ latitude, the $41.25^{\circ}$-latitude, the equator and the tip of South Africa as indicated in the top panel of Fig. 2. We focus on the averages of these broad boxes as we aim at robust results that are less dependent on potentially model-specific localized SL reactions.

\section{Relation of an Atlantic north-south disparity in SSH to the AMOC}

\section{$4.1 \quad 100 \mathrm{yr}$ of forcing}

For a total of $100 \mathrm{yr}$ and for a variety of forcing strengths, we present the relations of AMOC maximum and differences in sea-level change between $(\mathrm{N})$ and $(\mathrm{C})$ as well as $(\mathrm{N})$ and $(\mathrm{S})$. The target values of freshwater forcing (cf. Sect. 2) are varied between $0.06 \mathrm{~Sv}$ and $0.2 \mathrm{~Sv}$, the strength of the Southern Ocean wind stress by factors 0 to 4.0 ; the target values of $\mathrm{CO}_{2}$ concentration range from $350 \mathrm{ppm}$ to $1120 \mathrm{ppm}$. Two simulations with exponential increase of $\mathrm{CO}_{2}$ concentration ( $0.5 \%$ and $1.0 \%$ per year) are additionally included.
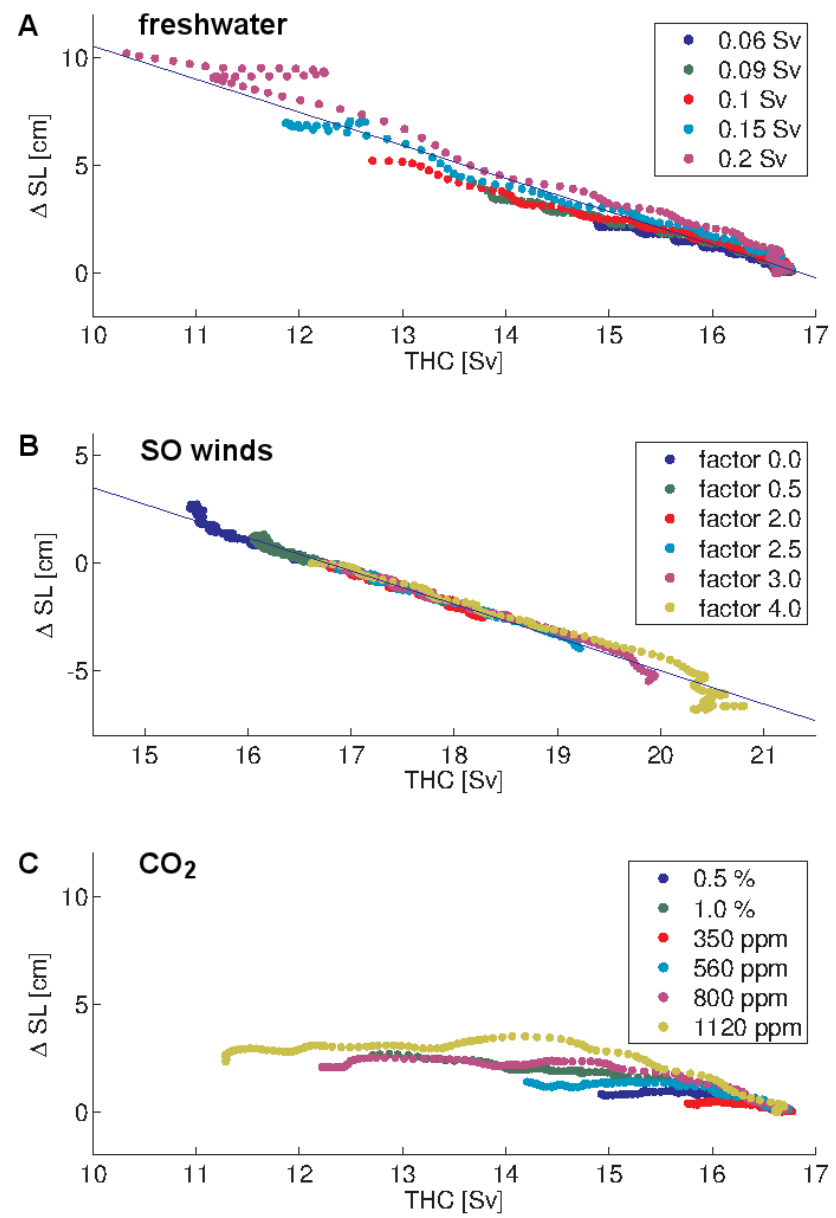

Fig. 3. $\triangle \mathrm{SL}$ between North and Central for the following forcings: (A) freshwater (slope: $-1.53 \mathrm{~cm} \mathrm{~Sv}^{-1}$ ), (B) Southern Ocean winds (slope: $\left.-1.54 \mathrm{~cm} \mathrm{~Sv}^{-1}\right),(\mathrm{C}) \mathrm{CO}_{2}$.

Plotted against the AMOC strength, Fig. 3 shows the difference in average sea level rise of the northern and the central part, and Fig. 4 between the northern and southern part. These two plots are quite similar, reflecting the fact that most significant relative displacements of SSH occur north of the equator, especially around the latitude of $40^{\circ}$. The main difference is the stronger reduction of $\Delta \mathrm{SL}_{\mathrm{NS}}$ compared to $\Delta S L_{N C}$ for $\mathrm{CO}_{2}$ forcing in the second half of the simulated timespan. Below, we will specifically comment on the peculiarities of thermal forcing (see Sect. 4.3); but for now, this motivates us to choose the difference between northern and central area as a representative of the SL rise gradient.

For the difference in sea-level change between these two areas in response to freshwater and wind stress forcing, each of the top and middle panels of Fig. 3 also shows an objective linear least square fit giving a slope of $-1.53 \mathrm{~cm} \mathrm{~Sv}^{-1}$ and $-1.54 \mathrm{~cm} \mathrm{~Sv}^{-1}$, respectively. These relations are consistent with the linearity found for freshwater forcing by Lorbacher et al. (2010) and show its apparent robustness for a range of different forcing strengths. The slope in Fig. 3 

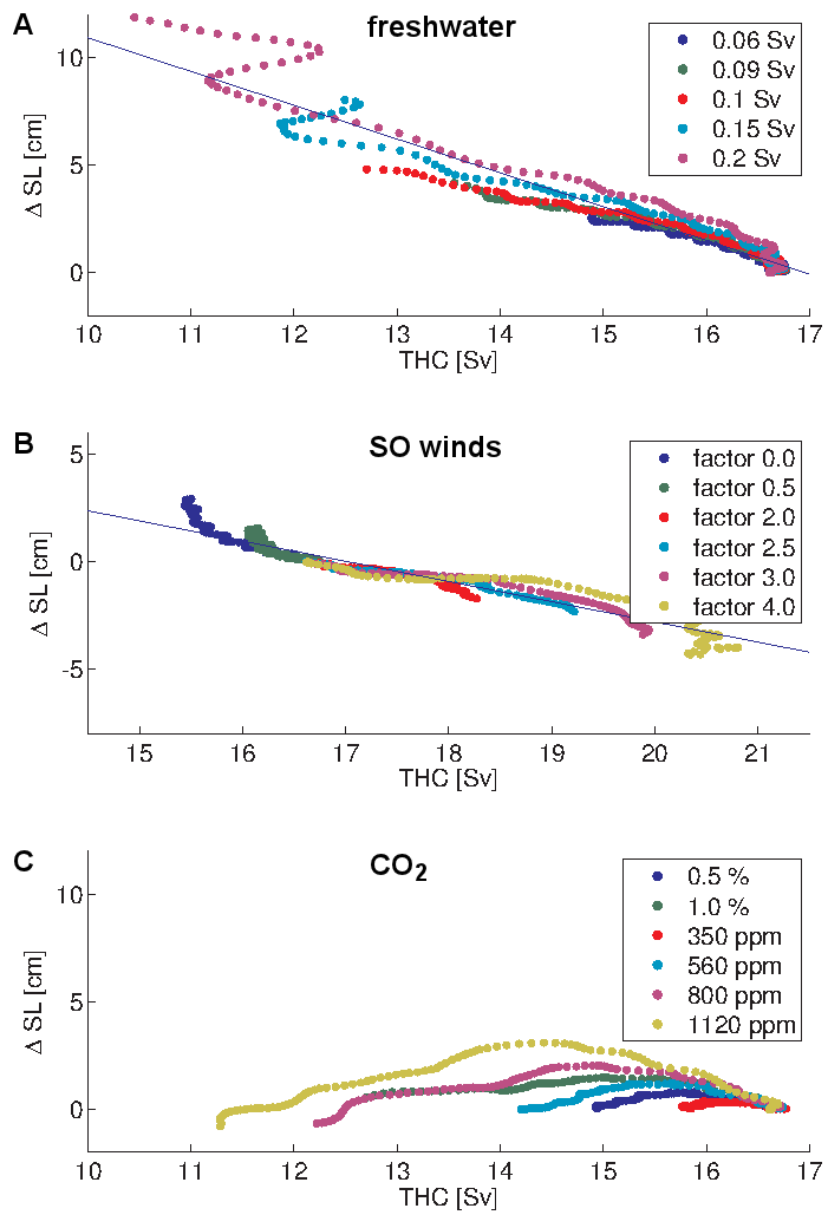

Fig. 4. $\Delta$ SL between North and South for the following forcings: (A) freshwater (slope: $-1.57 \mathrm{~cm} \mathrm{~Sv}^{-1}$ ), (B) Southern Ocean winds (slope: $-0.94 \mathrm{~cm} \mathrm{~Sv}^{-1}$ ), (C) $\mathrm{CO}_{2}$.

appears consistent with the map of dynamic sea-level change per Sverdrup of AMOC reduction given by Lorbacher et al. (2010) and presented in their Fig. 8a. However, increases of $\mathrm{CO}_{2}$ concentration lead to more non-linear relations when time progresses. This makes it essentially impossible to diagnose an AMOC change from relative SL rise in this manner. But note that the initial slope of the stronger forcings is quite similar to the one originating from the first two forcing types, which may be an indicator for an initially universal behavior.

In a different setting of almost no vertical diffusivity and for equilibrium states, Griesel and Maqueda (2006) analyze among other aspects the relation between AMOC and sea surface height when the density structure of the ocean is modified. This modification is done especially by altering Gent-McWilliams coefficients, but also by surface forcings including freshwater and wind as well as an increase in vertical diffusivity. Having a different objective, we look at the transient behavior and all of our forcings are combined with a realistic rather than almost zero vertical diffusivity, while considering different forcings with a range of
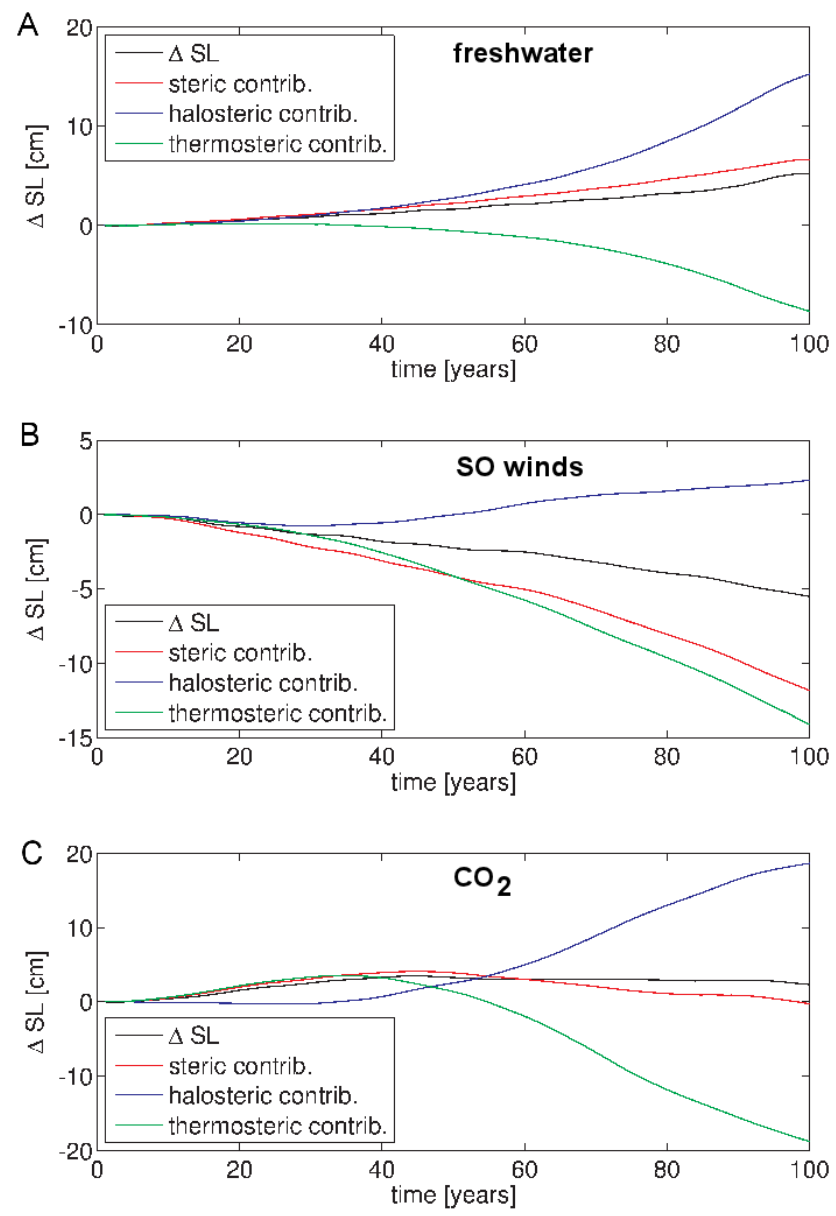

Fig. 5. $\Delta$ SL between North and Central and the contributions due to steric SLR as well as a subdivision into halosteric and thermosteric SLR: (A) freshwater forcing (0.1 Sv), (B) Southern Ocean winds (factor 3.0), (C) linear increase of $\mathrm{CO}_{2}$ to $1120 \mathrm{ppm}$.

strengths. However, some further universality of our above relations for freshwater and wind forcing is indicated by the quite similar linear relation between SSH difference ([40 to $60^{\circ} \mathrm{N}$ ] minus $\left[20^{\circ}\right.$ to $30^{\circ} \mathrm{N}$ ], at a longitude of $44^{\circ} \mathrm{W}$ ) and AMOC with a slope of about $-2 \mathrm{~cm} \mathrm{~Sv}^{-1}$ observed by Griesel and Maqueda (2006).

While we have also analyzed the consequences of including all latitudes from Antarctica to the North Pole and sectioning this extended Atlantic (not shown), the inclusion of the Southern Ocean does not produce the apparently robust linear relations seen in Fig. 3a and $b$, because the positive and negative changes around the ACC do not balance out and thus interfere with the relation found in the Atlantic further north.

The different contributions to the difference in SL change from steric, and more specifically thermosteric and halosteric, SLR are shown in Fig. 5 for one example of each forcing type. While large halosteric and thermosteric contributions almost cancel in case of $\mathrm{CO}_{2}$ forcing, the 
halosteric effect dominates in the freshwater case and the thermosteric effect dominates in case of modified Southern Ocean winds. The significant role of mass redistribution (the difference between total SL change and the steric contribution) is remarkable.

\subsection{Longer timescale}

For checking in how far the relations are dependent on the continuous increase of the forcing and on the relatively short timescale of $100 \mathrm{yr}$, we did two further analyses. Firstly, we have included the evolution of AMOC and SL for another $100 \mathrm{yr}$ in which we keep the forcing constant at its target value. Secondly, we have performed a set of experiments in which also $200 \mathrm{yr}$ of data are included but now with a slower increase of the forcing so that the target value is only reached at the end of this $200-\mathrm{yr}$ period.

Including the additional $100 \mathrm{yr}$ of the first case, the results deviate significantly from the original ones and neither of the two approximately linear relations is confirmed for this time period. The same is valid for the second set of 200-yr experiments, although the deviations are smaller. This illustrates the limitations of the transient relations. At this point, the tracer redistribution seems to lead to a state in which the vertical structure of density changes has sufficient time to change so that the relation between changes in depth-integrated transport and sea level is modified. It is noticeable that the linear relation breaks down for especially strong AMOC changes in Sect. 4.1. However, during the second century (at least in some of the simulations) no further reduction of the AMOC strength goes along with the breakdown of the linear relation. This indicates that the cause for the breakdown is not the amount of the AMOC change itself but the strength of the forcing combined with its timescale.

One may now wonder if the system approaches an equilibrium on a longer timescale when a linear relation between AMOC and sea level might be reestablished. Therefore, we have extended the original runs with constant forcing up to the year 1000. Figure 6 covers the last $10 \mathrm{yr}$ of the simulation, also illustrating the changes still occurring at this point of time. The slopes found in Sect. 4.1 are plotted into Fig. 6 for reference.

In case of freshwater forcing, the data is still scattered along a linear relation but with roughly double the slope and a different offset. This shows that with the continuous accumulation of freshwater, the impact on the sea level difference between north and center gets larger while the AMOC only weakens relatively little after the first $100 \mathrm{yr}$. For modified Southern Ocean wind stress, the situation is quite the opposite. When the wind stress is held constant after an increase, the AMOC continues to intensify and reaches maxima that are significantly larger after $1000 \mathrm{yr}$. The consequence is a linear best fit with a smaller slope. However, a significantly stronger weakening of the AMOC cannot be achieved via a weakening of the Southern Ocean winds even on this long
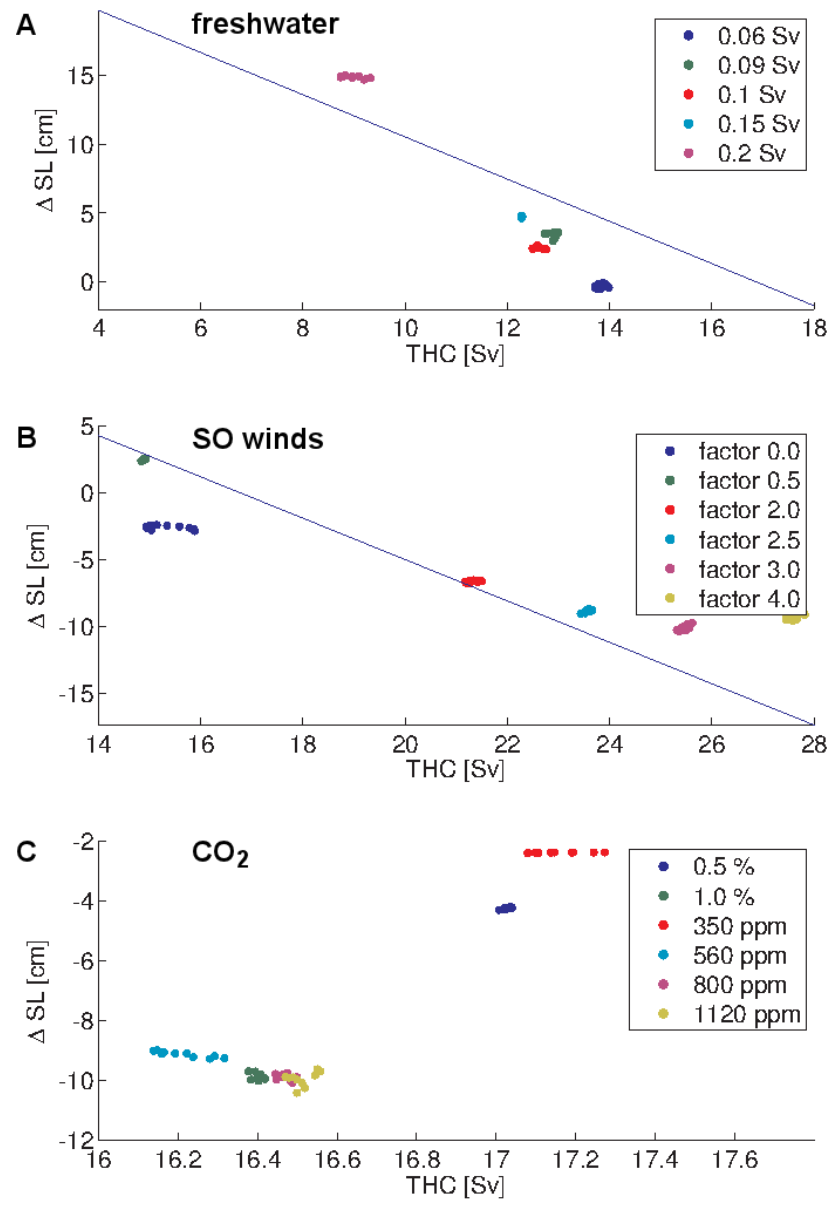

Fig. 6. $\Delta S L_{N C}$ after $1000 \mathrm{yr}$ for the following forcings: (A) freshwater, (B) Southern Ocean winds, $(\mathbf{C}) \mathrm{CO}_{2}$. The lines in the upper two panels follow Fig. 3 .

timescale and the linear fit is not as good as in the freshwater forcing case. For both types of simulations, the vertical profile of density changes gets modified in the longer run compared to the first $100 \mathrm{yr}$. This means that a preexisting specific linear relation between changes in the sea-level differences and in the depth-integrated pressure differences will degrade, no matter if there is a continuous linear scaling between the latter and the AMOC or not.

It was suggested a long time ago that the AMOC strength recovers approximately to its original value when an equilibrium state with higher $\mathrm{CO}_{2}$ concentration is reached: Manabe and Bryan (1985) argue that this is due to a compensation between polar amplification and the structure of the equation of state (Manabe and Bryan, 1985). More recently, Levermann et al. (2007) show the dependence of final AMOC changes on the initial strength because of sea-ice effects. However, it is interesting to observe that in our case there was finally larger sea-level rise in the lower latitudes compared to the northern area even though the AMOC maximum has recovered to its original value (lower panel of Fig. 6). While this will be 


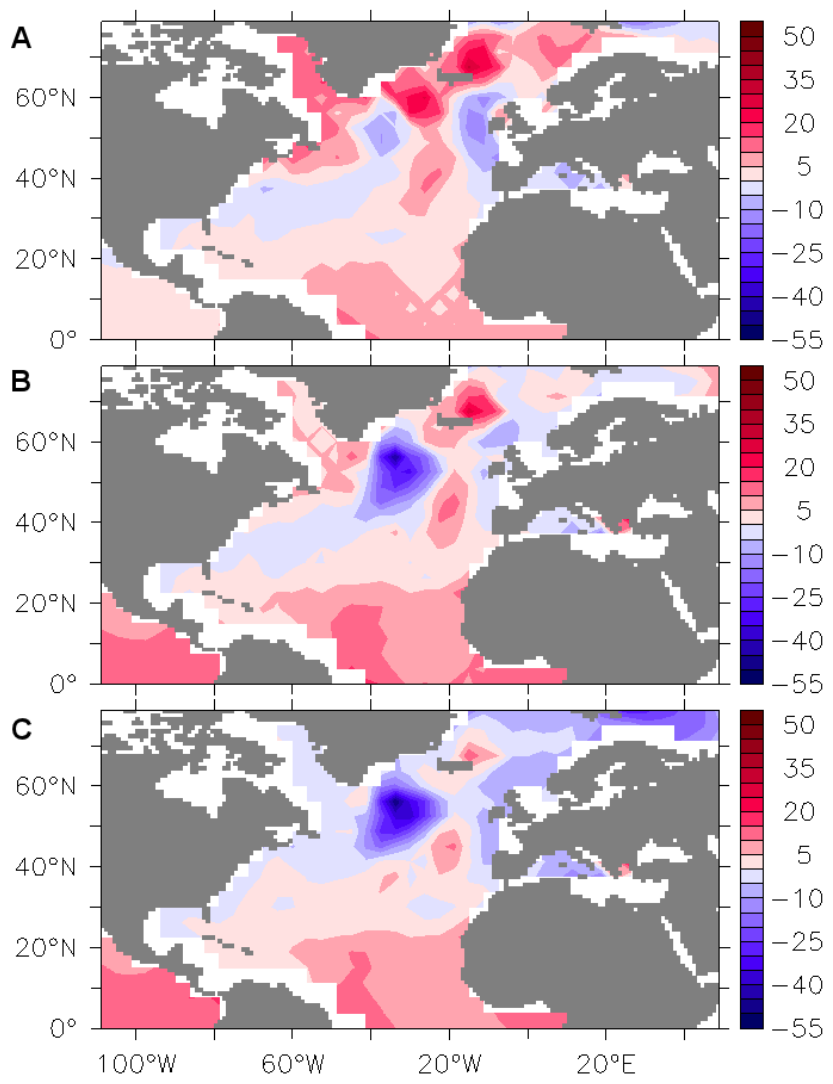

Fig. 7. Sea-level anomaly (zero global mean) in cm for linearly increasing $\mathrm{CO}_{2}$ concentration (to $1120 \mathrm{ppm}$ within $100 \mathrm{yr}$ ) at three different times: (A) year 100, (B) year 500, (C) year 1000.

discussed in the following subsection, we note that none of the relations described in the previous subsection is retained on the thousand year timescale.

\subsection{Special role of $\mathrm{CO}_{2}$ forcing}

The initial weakening followed by a recovery of the AMOC in case of $\mathrm{CO}_{2}$ forcing is easily understood: While as a first reaction the heat exchange in the deepwater-formation regions is reduced, instabilities of the water column can reoccur when the deeper ocean layers also have adjusted to the warmer climate. However, instead of vanishing when the AMOC is stabilized roughly at its original value, relative SLR is larger south of $30^{\circ} \mathrm{N}$ than north of $30^{\circ} \mathrm{N}$. This is also reflected by the negative $\Delta S L$ in the lower panel of Fig. 6 . Time slices of sea-level anomaly patterns in the North Atlantic (Fig. 7) illustrate this effect for a linear increase of $\mathrm{CO}_{2}$ concentration to $1120 \mathrm{ppm}$ within $100 \mathrm{yr}$ (concentration kept constant thereafter).
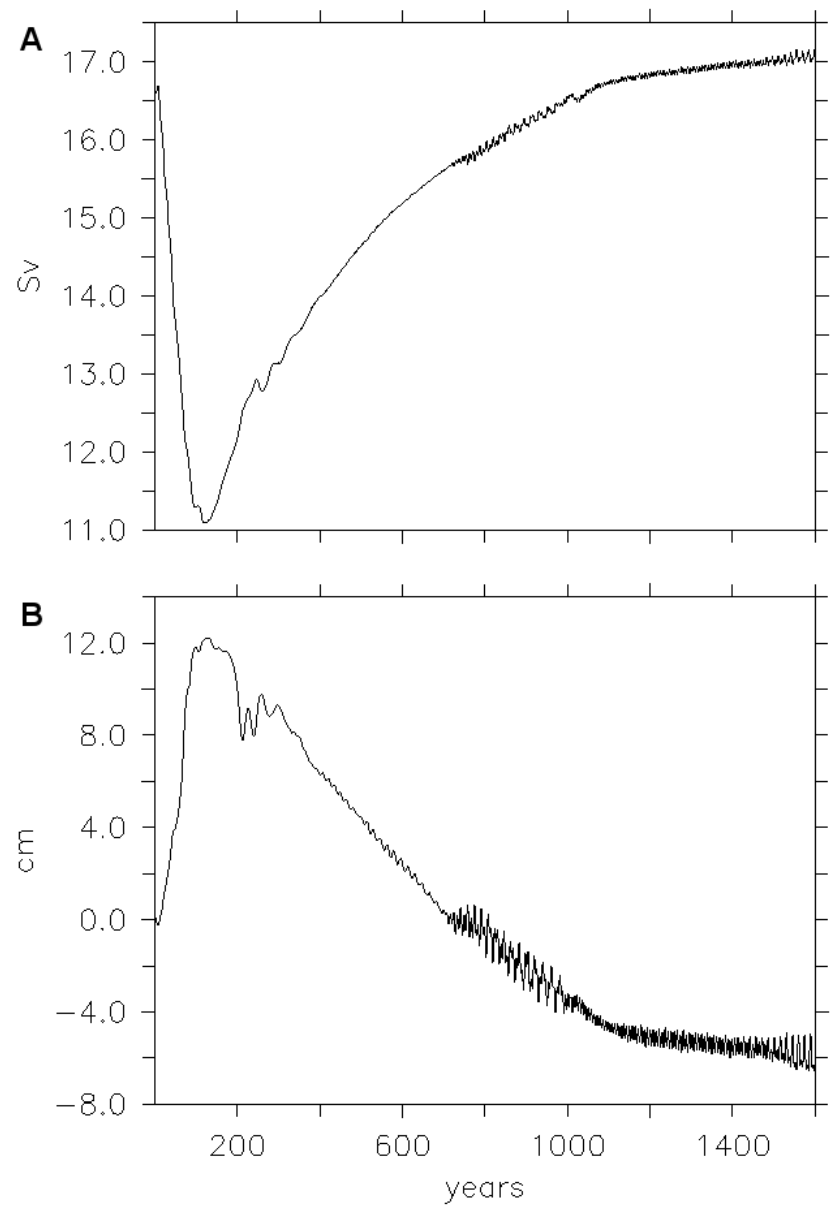

Fig. 8. (A) AMOC maximum, and (B) sea-level anomaly at the North American coast (zero global mean). $\mathrm{CO}_{2}$ concentration is linearly increased to $1120 \mathrm{ppm}$ within the first $100 \mathrm{yr}$.

Looking at the more local development, Fig. 8 shows a time series of the AMOC maximum and the average sea level of a fraction of the North American coast: between $41^{\circ} \mathrm{N}\left(1^{\circ}\right.$ north of New York City) and $60^{\circ} \mathrm{N}$. While the AMOC stabilizes, the transient SLR at the American coast is overcompensated, reaching a negative value rather than returning to the original equilibrium state.

Figure 9 shows the changes of potential density in the northern and the southern area. From the initially steeper slopes, it can be seen that density changes reach larger depths faster in the north. Thus, SLR in the early phase is more pronounced in this area. Later in the run, overall stronger density changes occur in the low latitudes, especially at a depth of around $400 \mathrm{~m}$, leading to a relatively larger SLR in the south. While initial salinity changes dominating in the upper $100 \mathrm{~m}$ and temperature changes dominating in larger depths both favour SLR in the north, later-on salinity changes (which in all depths favor stronger SLR in the north) are dominated by temperature changes leading to stronger SLR in the south. This thermal expansion can be understood as follows: water 

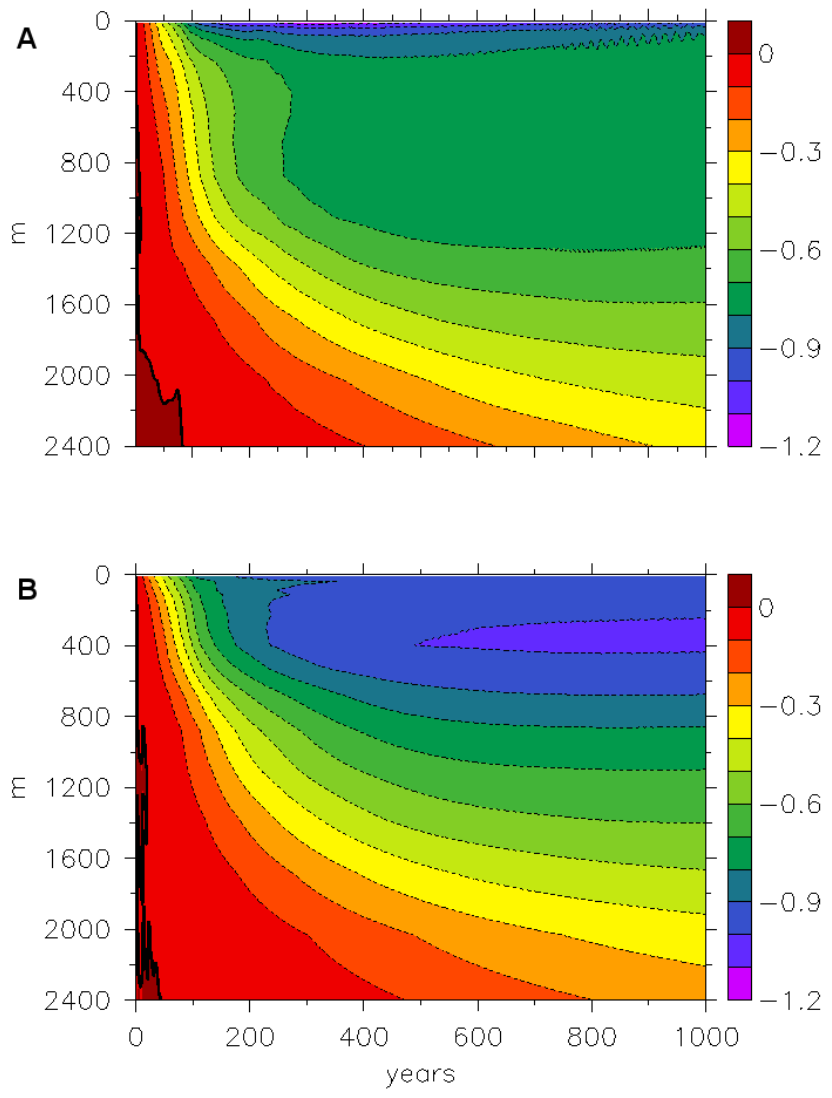

Fig. 9. Potential density anomaly $\left(\mathrm{kg} \mathrm{m}^{-3}\right)$ for linearly increasing $\mathrm{CO}_{2}$ concentration (to $1120 \mathrm{ppm}$ within $100 \mathrm{yr}$ ): (A) average of northern area, (B) average of central area.

in the top $200 \mathrm{~m}$ warms more strongly in the north, but density is reduced more strongly in the south because of the temperature dependence of the equation of state. However, the striking thermal expansion in the south centered around $400 \mathrm{~m}$ depth is due directly to stronger warming.

\subsection{Combined forcings based on RCP scenarios}

After this highly idealized study of fully independent forcing types, let us now turn to somewhat more realistic scenarios. The initial condition of the following simulations is produced by an integration over the time period between 1767 and 2005 on the basis of RCP historical forcing data (Meinshausen et al., 2011b). For the years 2006 to 2100, we have simulated all 4 RCP scenarios and an additional set of experiments in which we have also included high estimates of idealized Greenland freshwater forcing with target values of 0.042 to $0.13 \mathrm{~Sv}$. The RCP forcing as applied by us consists of greenhouse gases, direct effects of sulphate aerosols, landuse change and solar variability. For the historic forcing leading to the initial condition, volcanic forcing was also taken into account.
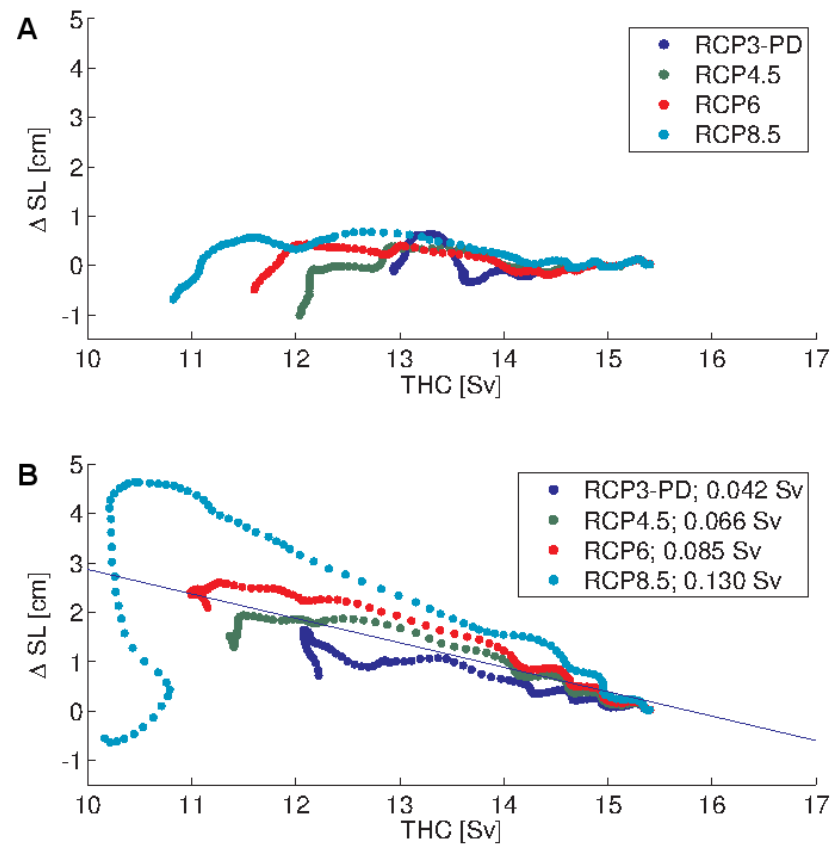

Fig. 10. $\Delta \mathrm{SL}_{\mathrm{NC}}$ for $100 \mathrm{yr}$ relative to 2005 for the following forcings: (A) 4 RCP-scenarios, (B) RCP-scenarios plus freshwater forcing (slope of linear fit: $-0.50 \mathrm{~cm} \mathrm{~Sv}^{-1}$ ).

Changes in the hydrological cycle are automatically reflected in the simulations. However, the freshwater flux due to meltwater runoff from Greenland has to be separately estimated. As its magnitude is highly uncertain, we have based our study on a best guess with the aim to see how parallel application of $\mathrm{CO}_{2}$ and freshwater forcing behave in principle. As in the preceding subsections, we linearly increase the freshwater flux from 0 to its target value between the years 2006 and 2100, and we apply it to the same area as in the preceding subsections, not taking into account regional distributions due to the Greenland boundary currents.

For no future temperature change, we assume a constant current Greenland mass loss rate of $250 \mathrm{Gt} \mathrm{yr}^{-1}$ (Rignot et al., 2011) which corresponds to about $7 \mathrm{~cm}$ SLR until 2100. Motivated by the results of Pfeffer et al. (2008), we choose an accumulated mass loss of $54 \mathrm{~cm}$ until the year 2100 for the strongest scenario (RCP8.5). Linearly scaling the freshwater fluxes between these two values for the other scenarios on the basis of the median global temperatures reached in the year 2100 as calculated with MAGICC6 (Meinshausen et al., 2011a), we apply target values of $0.042 \mathrm{~Sv}, 0.066 \mathrm{~Sv}, 0.085 \mathrm{~Sv}$ and $0.13 \mathrm{~Sv}$ for the scenarios RCP3-PD, RCP4.5, RCP6 and RCP8.5 respectively. We then keep the fluxes fixed for another five years in order to compare a total of $100 \mathrm{yr}$ with the results of Sect. 4.1.

The results with and without freshwater forcing are presented in Fig. 10. The pure RCP-forcing scenarios provide a picture qualitatively similar to the case of idealized $\mathrm{CO}_{2}$ forcing, with respect to the relatively small impact on the 
sea-level difference as well as with respect to the shapes of the curves. When combining both forcings, we do see linear trends for the largest fraction of the $100 \mathrm{yr}$. However, the slopes are smaller than in case of pure freshwater forcing and they are significantly different between the scenarios. The large drop of the SLR difference in the last $30 \mathrm{yr}$ of the simulation with strongest forcing goes along with a strongly nonlinear strengthening of the Subpolar Gyre in our model (Levermann and Born, 2007). The results in Fig. 10 confirm that the approach as it is cannot be used for diagnosing a weakening of the AMOC under climate change, not even under the assumption of strong and fixed Greenland runoff going along with each of the RCP scenarios.

\section{Additivity of SSH patterns and AMOC strengths}

In the preceding section, we have shown relations between AMOC strength and an Atlantic sea level difference for three types of forcing, but they turned out to be unsuitable as an AMOC diagnostic. Possibly other models, preferably with a higher resolution, may reveal more fine-structured patterns of which each corresponds to AMOC changes under a specific forcing and which are likely different from each other (cf. Fig. 2). In that case, it would be essential that the AMOC changes belonging to the individual forcings as well as the corresponding patterns of sea-level change add up linearly. If this were true, one might be able to deduce the contributing patterns as well as the contributing and total AMOC reductions from the observed sea-level changes (which are in general caused by the simultaneous action of different forcings). However, already the case of RCP scenarios with additional meltwater fluxes in the previous section reveals that the AMOC reductions do not add up linearly. We examine this aspect further in this section.

\subsection{Additivity of SSH patterns}

We do not attempt a quantitative analysis of the linear regime for the different parameters. Instead, we aim at illustrating that the large-scale patterns of sea-level change simulated by our model can be superposed reasonably well for our example forcings.

We choose the case of $\mathrm{CO}_{2}$ increase by $1 \%$ per year, doubling of the Southern Ocean winds within $100 \mathrm{yr}$ and a freshwater flux with a target value of $0.09 \mathrm{~Sv}$. The sum of the sealevel anomalies after the first $100 \mathrm{yr}$ is compared with the pattern resulting from the application of all three types of forcing at the same time. In contrast to the simulations in the preceding two sections where we were interested in the isolated effects of specific forcings, we now have included the wind stress feedback instead of keeping the wind stress fixed at its climatological values. Figure 11 shows the patterns of the three individual forcings, while Fig. 12 shows the sum of the patterns, the pattern resulting from the application of all three

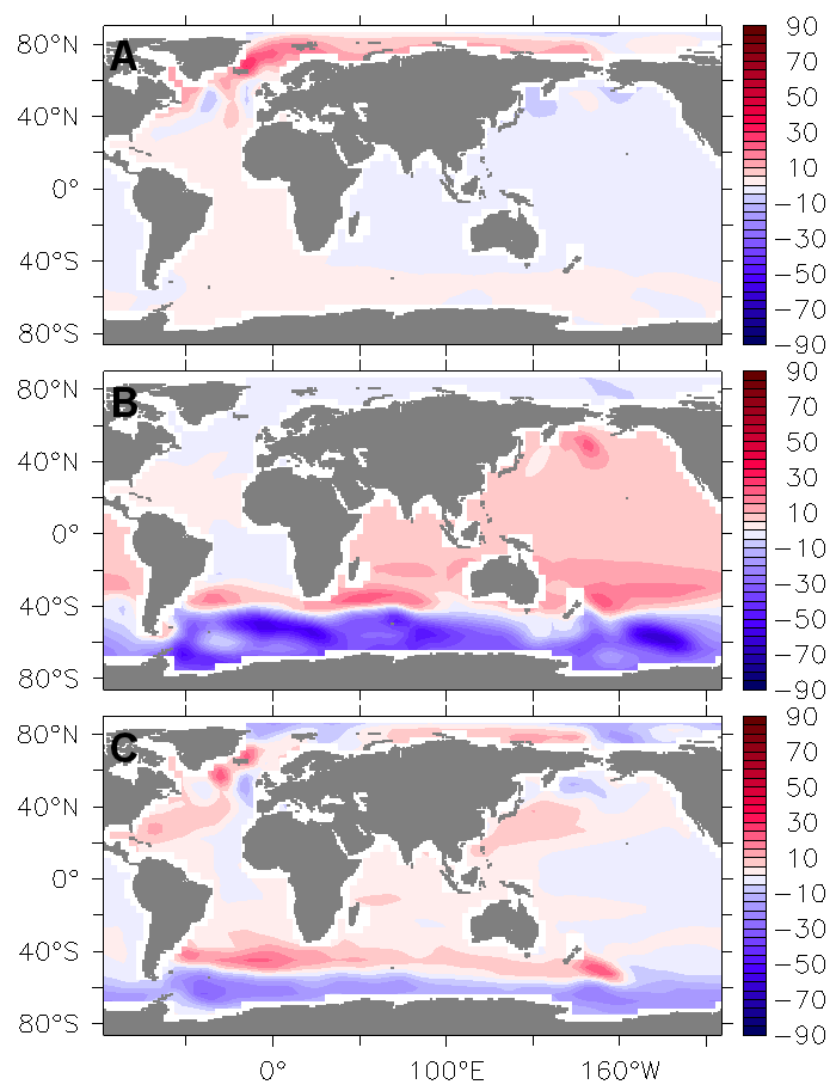

Fig. 11. Sea-level anomaly (cm) for individual forcings after $100 \mathrm{yr}$ : (A) freshwater, (B) SO winds, (C) $\mathrm{CO}_{2}$.

forcings and the difference between the two. Qualitatively, the patterns can be linearly superposed on a large scale. However, the regions of more pronounced non-linearity are those with a strong signal: the northern convection sites, the subpolar gyres and the ACC. This already influences the sea-level difference between the two areas $(\mathrm{N})$ and $(\mathrm{C})$ that we have discussed above.

\subsection{Additivity of AMOC weakening}

For checking the additivity of the individual changes in AMOC strength, we have applied the same forcings as in the preceding subsection. Figure 13 shows a time series of the first $200 \mathrm{yr}$. While the sum of the individual AMOC changes coincides very well with the anomaly due to combined forcing for the first $80 \mathrm{yr}$ and a total AMOC change of about $4 \mathrm{~Sv}$, we observe that they differ significantly thereafter.

This suggests that the range of applicability of a hypothetical AMOC diagnostic involving different SL change patterns for different forcings is limited.

The large fluctuations of the AMOC under freshwater forcing, especially in the last $50 \mathrm{yr}$, occur in correlation with fluctuations of the subpolar gyre strength (cf. Levermann and Born, 2007). While this variability does not occur under 


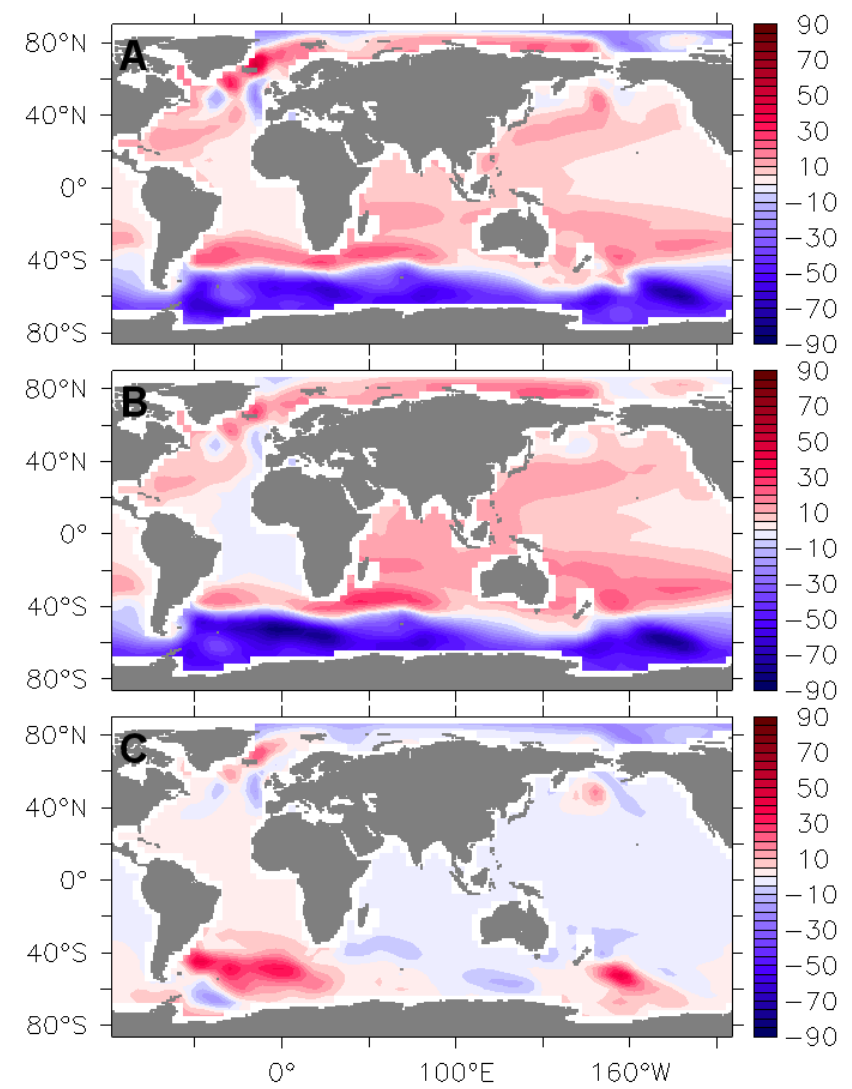

Fig. 12. (A) Sum of the three anomalous sea-level fields given in Fig. 11, (B) sea-level anomaly resulting from application of all three forcings, (C) difference of the fields in (A) and (B).

the same magnitude of freshwater-forcing if the wind-stress feedback is disabled, it does occur even without variable wind stress when applying some other forcing strengths.

\section{Conclusions}

We were aiming at identifying a robust transient relation between a gradient of sea-level change in the Atlantic and changes of the AMOC on the basis of an ensemble study with a coarse resolution model that parameterizes eddy fluxes. We did indeed find a linear relation for Southern Ocean wind and freshwater forcing, which has a slope of about $-1.5 \mathrm{~cm} \mathrm{~Sv}^{-1}$ with respect to the difference in sea-level change between two areas in the North Atlantic. While a somewhat similar slope was found for an initial short period of strong changes in $\mathrm{CO}_{2}$ concentration, this relation does not hold for the largest fraction of the simulations and is also dependent on the forcing strength. For each of the less idealized settings of four RCP scenarios with associated freshwater forcing motivated by Greenland meltwater runoff, transient linear relations of the SL difference and AMOC weakening are mainly confirmed. However, the slopes quantitatively differ between the different scenarios. Because of the great relevance of $\mathrm{CO}_{2}$

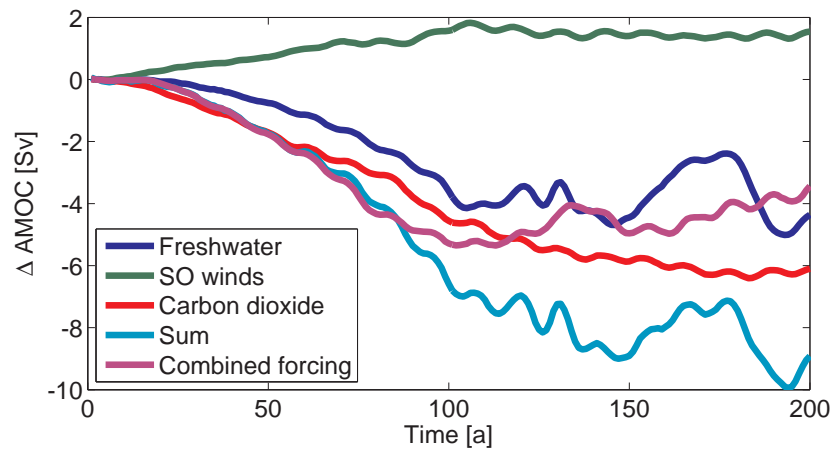

Fig. 13. AMOC changes for individual forcings and for combined forcing.

forcing, these results exclude using the sea-level difference or gradient as a direct AMOC diagnostic under climate change.

It is therefore desirable to focus on the analysis of more detailed patterns of sea-level change, which might lead to fingerprints for different forcing mechanisms similar to the sea-level patterns provided in Sect. 3. However, for such a study, more complex models based on a higher resolution are likely to be better suited. We demonstrated in a short outlook that individual large-scale patterns of SSH change as well as AMOC changes can be linearly superposed reasonably well for the given forcing strengths in a limited timeframe of $80 \mathrm{yr}$ (Figs. 12 and 13). Thus, if different relations for different forcing types are found in the future, they might be able to serve as an AMOC diagnostic under the realistic simultaneous action of several forcings; but the indicated limitations regarding additivity would have to be further explored.

Acknowledgements. We thank Georg Feulner and Till Kuhlbrodt for helpful discussions and we are grateful to the anonymous referees for their comments. H. K. acknowledges support by the Evangelisches Studienwerk Villigst e.V. and the German National Academic Foundation.

Edited by: K. Keller

\section{References}

Broecker, W. S.: Unpleasant surprises in the greenhouse?, Nature, 328, 123-126, 1987.

Bryan, F.: Parameter sensitivity of primitive equation ocean general circulation models, J. Phys. Oceanogr., 17, 970-985, 1987.

de Boer, A. M., Gnanadesikan, A., Edwards, N. R., and Watson, A. J.: Meridional density gradients do not control the Atlantic overturning circulation, J. Phys. Oceanogr., 40, 368-380, 2010.

Dohan, K. and Maximenko, N.: Monitoring ocean currents with satellite sensors, Oceanography, 23, 94-103, 2010.

Farneti, R. and Delworth, T. L.: The role of mesoscale eddies in the remote oceanic response to altered Southern Hemisphere winds, J. Phys. Oceanogr., 40, 2348-2354, 2010. 
Farneti, R., Delworth, T. L., Rosati, A. J., Griffies, S. M., and Zeng, F.: The role of mesoscale eddies in the rectification of the Southern Ocean response to climate change, J. Phys. Oceanogr., 40, 1539-1557, 2010.

Gent, P. R. and McWilliams, J. C.: Isopycnal mixing in ocean circulation models, J. Phys. Oceanogr., 20, 150-155, 1990.

Gnanadesikan, A.: A simple predictive model for the structure of the oceanic pycnocline, Science, 283, 2077-2079, 1999.

Gregory, J. M., Dixon, K. W., Stouffer, R. J., Weaver, A. J., Driesschaert, E., Eby, M., Fichefet, T., Hasumi, H., Hu, A., Jungclaus, J. H., Kamenkovich, I. V., Levermann, A., Montoya, M., Murakami, S., Nawrath, S., Oka, A., Sokolov, A. P., and Thorpe, R. B.: A model intercomparison of changes in the Atlantic thermohaline circulation in response to increasing atmospheric $\mathrm{CO}_{2}$ concentration, Geophys. Res. Lett., 32, L12703, doi:10.1029/2005GL023209, 2005.

Griesel, A. and Morales Maqueda, M. A.: The relation of meridional pressure gradients to North Atlantic deep water volume transport in an ocean general circulation model, Clim. Dynam., 26, 781799, 2006

Häkkinen, S.: Variability in sea surface height: A qualitative measure for the meridional overturning in the North Atlantic, J. Geophys. Res.-Oceans, 106, 13837-13848, 2001.

Hofmann, M. and Rahmstorf, S.: On the stability of the Atlantic meridional overturning circulation, P. Natl. Acad. Sci., 106, 20584-20589, 2009.

Hu, A. X., Meehl, G. A., and Han, W. Q.: Detecting thermohaline circulation changes from ocean properties in a coupled model, Geophys. Res. Lett., 31, L13204, doi:10.1029/2004GL020218, 2004.

Hughes, T. M. C. and Weaver, A. J.: Multiple equilibria of an asymmetric 2-basin ocean model, J. Phys. Oceanogr., 24, 619-637, 1994.

Ivchenko, V. O., Sidorenko, D., Danilov, S., Losch, M., and Schröter, J.: Can sea surface height be used to estimate oceanic transport variability?, Geophys. Res. Lett., 38, L11601, doi:10.1029/2011GL047387, 2011.

Kanzow, T., Hirschi, J. J. M., Meinen, C., Rayner, D., Cunningham, S. A., Marotzke, J., Johns, W. E., Bryden, H. L., Beal, L. M., and Baringer, M. O.: A prototype system for observing the Atlantic meridional overturning circulation - scientific basis, measurement and risk mitigation strategies, and first results, J. Operat. Oceanogr., 1, 19-28, 2008.

Körper, J., Spangehl, T., Cubasch, U., and Huebener, H.: Decomposition of projected regional sea level rise in the north Atlantic and its relation to the AMOC, Geophys. Res. Lett., 36, L19714, doi:10.1029/2009GL039757, 2009.

Kuhlbrodt, T., Griesel, A., Montoya, M., Levermann, A., Hofmann, M., and Rahmstorf, S.: On the driving processes of the Atlantic meridional overturning circulation, Rev. Geophys., 45, RG2001, doi:10.1029/2004RG000166, 2007.

Landerer, F. W., Jungclaus, J. H., and Marotzke, J.: Regional dynamic and steric sea level change in response to the IPCC-A1B scenario, J. Phys. Oceanogr., 37, 296-312, 2007.

Large, W. G., McWilliams, J. C., and Doney, S. C.: Oceanic vertical mixing: A review and a model with a nonlocal boundary layer parameterization, Rev. Geophys., 32, 363-403, 1994.

Latif, M., Roeckner, E., Botzet, M., Esch, M., Haak, H., Hagemann, S., Jungclaus, J., Legutke, S., Marsland, S., Mikolajewicz,
U., and Mitchell, J.: Reconstructing, monitoring, and predicting multidecadal-scale changes in the North Atlantic thermohaline circulation with sea surface temperature, J. Climate, 17, 16051614, 2004.

Latif, M., Boning, C., Willebrand, J., Biastoch, A., Dengg, J., Keenlyside, N., Schweckendiek, U., and Madec, G.: Is the thermohaline circulation changing?, J. Climate, 19, 4631-4637, 2006.

Lee, T., Häkkinen, S., Kelly, K., Qiu, B., Bonekamp, H., and Lindstrom, E. J.: Satellite observations of ocean circulation changes associated with climate variability, Oceanography, 23, 70-81, 2010.

Levermann, A. and Born, A.: Bistability of the Atlantic subpolar gyre in a coarse-resolution climate model, Geophys. Res. Lett., 34, L24605, doi:10.1029/2007GL031732, 2007.

Levermann, A., Griesel, A., Hofmann, M., Montoya, M., and Rahmstorf, S.: Dynamic sea level changes following changes in the thermohaline circulation, Clim. Dynam., 24, 347-354, 2005.

Levermann, A., Mignot, J., Nawrath, S., and Rahmstorf, S.: The role of northern sea ice cover for the weakening of the thermohaline circulation under global warming, J. Climate, 20, 41604171, 2007.

Lorbacher, K., Dengg, J., Böning, C. W., and Biastoch, A.: Regional patterns of sea level change related to interannual variability and multidecadal trends in the Atlantic meridional overturning circulation, J. Climate, 23, 4243-4254, 2010.

Manabe, S. and Bryan Jr., K.: $\mathrm{CO}_{2}$-Induced change in a coupled Ocean-Atmosphere model and its paleoclimatic implications, J. Geophys. Res., 90, 11689-11707, 1985.

Manabe, S. and Stouffer, R. J.: Century-scale effects of increased atmospheric $\mathrm{CO}_{2}$ on the ocean-atmosphere system, Nature, 364 , 215-218, 1993.

Meehl, G. A., Stocker, T. F., Collins, W. D., Friedlingstein, P., Gaye, A. T., Gregory, J. M., Kitoh, A., Knutti, R., Murphy, J. M., Noda, A., Raper, S. C. B., Watterson, I. G., Weaver, A. J., and Zhao, Z.C.: Climate Change 2007: The Physical Science Basis, Contribution of Working Group I to the Fourth Assessment Report of the Intergovernmental Panel on Climate Change, Chap. Global Climate Projections, Cambridge University Press, Cambridge, UK and New York, NY, USA, 2007.

Meinshausen, M., Wigley, T. M. L., and Raper, S. C. B.: Emulating atmosphere-ocean and carbon cycle models with a simpler model, MAGICC6 - Part 2: Applications, Atmos. Chem. Phys., 11, 1457-1471, doi:10.5194/acp-11-1457-2011, $2011 \mathrm{a}$.

Meinshausen, M., Smith, S. J., Calvin, K., Daniel, J. S., Kainuma, M. L. T., Lamarque, J.-F., Matsumoto, K., Montzka, S. A., Raper, S. C. B., Riahi, K., Thomson, A., Velders, G. J. M., and van Vuuren, D. P. P.: The RCP greenhouse gas concentrations and their extensions from 1765 to 2300, Climatic Change, 109, 213-241, $2011 b$.

Montoya, M., Griesel, A., Levermann, A., Mignot, J., Hofmann, M., Ganopolski, A., and Rahmstorf, S.: The earth system model of intermediate complexity CLIMBER-3 $\alpha$, Part 1: description and performance for present-day conditions, Clim. Dynam., 25, 237 263, 2005.

Pacanowski, R. C. and Griffies, S. M.: The MOM3 manual, Geophysical fluid dynamics Laboratory/NOAA, Princeton, USA, 680, 1999. 
Petoukhov, V., Ganopolski, A., Brovkin, V., Claussen, M., Eliseev, A., Kubatzki, C., and Rahmstorf, S.: CLIMBER-2: a climate system model of intermediate complexity, Part I: model description and performance for present climate, Clim. Dynam., 16, 1-17, 2000.

Pfeffer, W. T., Harper, J. T., and O'Neel, S.: Kinematic constraints on glacier contributions to 21st-Century Sea-Level rise, Science, 321, 1340-1343, 2008.

Redi, M. H.: Oceanic isopycnal mixing by coordinate rotation, J. Phys. Oceanogr., 12, 1154-1158, 1982.

Rignot, E., Velicogna, I., van den Broeke, M. R., Monaghan, A., and Lenaerts, J.: Acceleration of the contribution of the Greenland and Antarctic ice sheets to sea level rise, Geophys. Res. Lett., 38, L05503, doi:10.1029/2011GL046583, 2011.

Spence, Pa., Fyfe, J. C., Montenegro, A., and Weaver, A. J.: Southern Ocean Response to Strengthening Winds in an EddyPermitting Global Climate Model, J. Climate, 23, 5332-5343, 2010.
Stommel, H.: Thermohaline convection with 2 stable regimes of flow, Tellus, 13, 224-230, 1961.

Thorpe, R. B., Gregory, J. M., Johns, T. C., Wood, R. A., and Mitchell, J. F. B.: Mechanisms determining the Atlantic thermohaline circulation response to greenhouse gas forcing in a nonflux-adjusted coupled climate model, J. Climate, 14, 3102-3116, 2001.

Willis, J. K.: Can in situ floats and satellite altimeters detect longterm changes in Atlantic ocean overturning?, Geophys. Res. Lett., 37, L06602, doi:10.1029/2010GL042372, 2010.

Yin, J. J., Schlesinger, M. E., and Stouffer, R. J.: Model projections of rapid sea-level rise on the northeast coast of the United States, Nat. Geosci., 2, 262-266, 2009. 